\section{SAT0002 COMPARISON OF TWO EXERCISE REGIMENS IN PATIENTS WITH ANKYLOSING SPONDYLITIS}

KK Trnavsky, Y Sulcova, J Knebortova. Rheumatology, Postgraduate Medical School, Arthocentrum, Praha, Czech Republic

10.1136/annrheumdis-2001.354

Background Exercise alone can produce adequate relief of symptoms in ankylosing spondylitisi (AS) and manipulative therapy has also been shown to improve range of movement in short ? time.

Objectives To compare the effect of a dynamic individual rehabilition regimen with a simple conservative exercise regimen (exercies in goups).

Methods Forty patients with established AS, mean age 51 years and mean disease duration 10 years were randomly assigned to group of 20 patients each. The treatment programme consisted of two thre ? months periods.: A. Intensive individual programme (assisted by an experienced physiotherapist) included thermotherapy. Soft techniques, relaxation of shortened muscles, breathing exercises. B. Current exercise programme in groups. Metrologic assessment and questionnaires were used to evaluate the activity of the process (BASDAI) and the functional handicap of the patient (BASFI). In the first group of patients both the programme A and B were applied. The second group underwent only programme B. After 3 months the therapeutic programmes in the two groups were exchanged.

Results The combined exercise regimen involving individual therapeutic care resulted in improvement of parameters assessing spinal column mobility ? Schober "s distance, tips to the floor distance, incluination and retro ? and anteflexion of cervical column. The indicators of function and disease activity evaluated according to BASDAI and BASFI questionnaires showed also improvement but the differences did no reach statistical significance over the three-months period of follow-up.

Conclusion Intensive individual exercise programme including soft techniques and relaxation of shortened muscles is more effective in AS than a conservative programme based on exercise in groups.

\section{SAT0003 INTESTINAL COLONISATION WITH SULPHATE-REDUCING BACTERIA: A CO-FACTOR IN THE AETIOPATHOGENESIS OF ANKYLOSING SPONDYLITIS?}

${ }^{1} \mathrm{SM}$ Stebbings, ${ }^{1} \mathrm{~J}$ Highton, ${ }^{2} \mathrm{G}$ Tannock. ${ }^{1}$ Rheumatology; ${ }^{2}$ Microbiology, University of Otago School of Medicine, Dunedin, New Zealand

\subsection{6/annrheumdis-2001.355}

Background Sulphate-reducing bacteria (SRB) have only recently been identified as a constituent of the normal colonic microflora humans. Such colonisation however is far from universal. Small studies in patients with ulcerative colitis (UC) have found SRB to be present in up to $92 \%$ of patients and a pathogenic role has been speculated. Approximately $65 \%$ of patients with ankylosing spondylitis (AS) have colonic inflammation, and this is now recognised as an independent risk factor for the disease. Furthermore, studies in germfree HLA-B27 transgenic rats have shown that the normal intestinal microflora is essential to the development of spondyloarthritis in these animals.

Objectives We aimed to discover whether intestinal colonisation with SRB was more common in AS patients than controls, and thus whether SRB may play a role in the aetiology of AS.
Methods Fifteen patients fulfilling the Modified New York criteria for AS and 15 age and gender matched controls were recruited. Each subject provided 3 faecal specimens at monthly intervals. Bacterial DNA extracts were obtained from 3 faecal samples from 14 patients and 14 controls, and one each from the remaining patient and control. PCR was performed using primers targeting a conserved region of subunit $\mathrm{A}$ of the adenosine-5?-phosphosulphate (APS) reductase gene a gene conserved across all SRB species.

Results (See Table 1)

Chi-square with Yates? correction demonstrated a highly significant association between AS and colonisation with SRB ( $\mathrm{p}=$ 0.003).

\begin{tabular}{llll}
\multicolumn{4}{l}{ Abstract SAT0003 } \\
\hline & Pable 1 & & \\
\hline Ankylosing spondylitis & $24(56 \%)$ & $19(44 \%)$ & 43 \\
Controls & $7(16 \%)$ & $36(84 \%)$ & 43 \\
Total number of samples & & & 86 \\
\hline Identification of sulphate-reducing bacteria in faecal samples using PCR.
\end{tabular}

Conclusion We have discovered a much higher prevalence of faecal carriage of SRB in patients with AS compared with healthy controls. This raises the possibility that these organisms may play a role in the aetiopathogenesis of AS. An alternative possibility is that SRB reflect the presence of colonic inflammation in these individuals.

\section{REFERENCES}

1 Gibson GR, Cummings JH, Macfarlane GT. Growth and activities of sulphatereducing bacteria in gut contents of healthy subjects and patients with ulcerative colitis. FEMS Microbiol Ecol. 1991;86:103-12

2 Veys EM, Mielants $H$, De Vos M, Cuvelier C. Spondylarthropathies: from gut to target organs. Baillieres Clin Rheumatol. 1996;10(1):123-46

3 Taurog JD, Richardson JA, Croft JT, et al. The germfree state prevents development of gut and joint inflammatory disease in HLA-B27 transgenic rats. J Exp Med. 1994;180(6):2359-64

\section{SATO004 IS THE ASSOCIATION SJÖGREN'SYNDROME- SPONDYLARTHROPATHY FORTUITOUS?}

C Scotto di Fazano, E Quennesson, S Quennesson, RM Grilo, D Couaral, P Vergne, C Bonnet, P Bertin, R Treves. Rheumatology, Universitary Hospital Dupuytren, Limoges, France

\subsection{6/annrheumdis-2001.356}

Background Secondary Sjögren's syndrome is known to occur with rheumatoid arthritis, systemic lupus erythematosus, but apart from a few cases, has not been reported with spondylarthropathy (SpA).

Objectives To determine the prevalence of Sjögren's syndrome in spondylarthropathy patients.

Methods Patients with SpA ( $\mathrm{n}=62)$ with inflammatory back pain and/or peripheral arthritis were diagnosed as Ankylosing Spondylitis (AS), undifferentiated SpA (uSpA), psoriatic Arthritis (PA), and arthritis associated with inflammatory bowel diseases (IBD). The investigation of sicca symptoms in the group SPD and healthy controls $(n=102)$ was based on a valited questionnaire. Patients with $\mathrm{SpA}$ with sicca symptomes and/or positive antinuclear antibodies (ANA) were investigated for Sjögren's syndrome by minor salivary gland biopsy. 